\title{
Diagnostic Issues of Depressive Disorders from Kraepelinian Dualism to the Diagnostic and Statistical Manual of Mental Disorders, Fifth Edition
}

\author{
Seon-Cheol Park ${ }^{1}$ and Yong-Ku Kim ${ }^{2} \bowtie$ \\ ${ }^{1}$ Department of Psychiatry, Inje University Haeundae Paik Hospital, Busan, Republic of Korea \\ ${ }^{2}$ Department of Psychiatry, Korea University Ansan Hospital, Korea University College of Medicine, Seoul, Republic of Korea
}

\begin{abstract}
Because the Diagnostic and Statistical Manual of Mental Disorders, 4th edition (DSM-IV) was mainly influenced by the neo-Kraepelinian approach, its categorical approach to defining mental disorders has been criticized from the viewpoint of etiological neutrality. In the context of bridging the gap between "presumed etiologies-based symptomatology" and "identifiable pathophysiological etiologies," the content in 5th edition, the DSM-5, has been revised to incorporate a combination of categorical and dimensional approaches. The most remarkable change of note regarding the diagnostic classification of depressive disorders in the DSM-5 is the splitting of mood disorders into bipolar disorders and depressive disorders, which is in accordance with the deconstruction of the Kraepelinian dualism for psychoses. The transdiagnostic specifiers "with mixed features," "with psychotic features," and "with anxious distress" are introduced to describe the relationships of depressive disorders with bipolar disorders, schizophrenia, and generalized anxiety disorder, respectively, in a dimensional manner. The lowering of the diagnostic threshold for major depressive disorder (MDD) may be caused by the addition of "hopelessness" to the subjective descriptors of depressive mood and the elimination of "bereavement exclusion" from the definition of MDD. Since the heterogeneity of MDD is equivalent to the Wittgensteinian "games" analogy, the different types of MDD are related not by a single essential feature but rather by "family resemblance." Network analyses of MDD symptoms may therefore need further review to elucidate the connections among interrelated symptoms and other clinical elements. Psychiatry Investig 2019;16(9):636-644
\end{abstract}

Key Words Major depressive disorder, Categorical approach, Dimensional approach, Diagnostic and Statistical Manual of Mental Disorders, Network analysis.

\section{INTRODUCTION}

The Diagnostic and Statistical Manual of Mental Disorders (DSM) has a tendency to resist change and the revision of its content, consistent with the statement that "the Catholic Church changes its Pope more often than the American Psychiatric Association (APA) publishes a new version of the DSM." The DSM has been revised five times between 1952 and 2013. The first incarnations, the DSM-I (1952) and DSM-II (1968) were based on psychoanalytic and psychodynamic theories and had shortcomings in terms of their arbi-

Received: July 2, 2019 Revised: September 4, 2019

Accepted: September 6, 2019

$\triangle$ Correspondence: Yong-Ku Kim, MD, PhD

Department of Psychiatry, Korea University Ansan Hospital, Korea University College of Medicine, 123 Jeokgeum-ro, Danwon-gu, Ansan 15355, Republic of Korea

Tel: +82-31-412-5140, Fax: +82-31-412-5144, E-mail: yongku@korea.ac.kr

(ac) This is an Open Access article distributed under the terms of the Creative Commons Attribution Non-Commercial License (https://creativecommons.org/licenses/bync/4.0) which permits unrestricted non-commercial use, distribution, and reproduction in any medium, provided the original work is properly cited. trariness and inconsistency in defining the diagnoses for mental disorders. The "DSM-III revolution (1980)," which refers to the increasing trends that occurred in logical positivism and biological psychiatry, was subsequently proposed in order to overcome criticism based on the Rosenhan experiment findings, the antipsychiatry movement, and public debates regarding the distinctive unclearness of the DSM-I and DSM-II. Thus, in the DSM-III, mental disorders were defined from a categorical viewpoint that was based on the operational diagnostic system characterized by a descriptive approach, explicit inclusion and exclusion criteria, algorithms for diagnostic criteria, a nominalist definition, etiological neutrality, and a quantitative approach. Then, in the DSM-IV (1994), consistent with empirical trends, the tendency to define psychiatry as a part of biomedicine was further strengthened., ${ }^{2,3}$

Steven Hyman, ${ }^{1}$ a former director of the National Institute of Mental Health, criticized the DSM, saying "the problem is that (the) DSM has been launched into under-researched 
waters, and this has been accepted in an unquestioning way." Thus, the construction of a "paradigm shift in psychiatry" from a "symptom-based classification system" to an "etiology-based classification system" was proposed during the revision process of the DSM-5. ${ }^{4-6}$ Since the DSM-5 task force realized, however, that this goal was wildly premature, a dimensional approach characterized by the introduction of numerical scales was alternatively regarded as its major innovation. It was thus suggested that dimensional measurements rather than diagnostic categories contribute to a valid, biologically based, and scientifically sound classification system in psychiatry. ${ }^{7}$ However, the dimensional scales were relegated to the appendix of the DSM- 5 for further study by the APA assembly since the severity scales were not validated and an undue burden was imposed upon clinicians. ${ }^{8}$ Moreover, an editorial article authored by Allan Frances, ${ }^{9}$ who had been the chair of the DSM-IV task force, titled "Diagnosing the DSM," was published in the New York Times on May 11, 2012. In this article, the DSM-5 was labeled a "promise to be a disaster." As a result, a combination of categorical and dimensional approaches was introduced for the definition of mental disorders in the DSM-5 (2013), since the aims of the DSM-5 task force shifted toward bridging the gap between "presumed etiologies-based symptomatology" and "identifiable pathophysiological etiologies." ${ }^{10}$ The failure of the task force to achieve a radical paradigm shift was explained as the result of "grand ambition, furious resistance, and the derailment of the DSM-5 revision process," by Whooley and Horowitz. However, the DSM-5 revision process has also been praised for "opening the door to questions about future psychiatry" in terms of categorical and dimensional approaches to mental disorders. Table 1 summarizes the changes in diagnostic classifications and criteria for depressive disorders between the DSM-IV and DSM-5. ${ }^{11,12}$ Herein, we sought to review and discuss the categorical and dimensional approaches to depressive disorders in the context of the changes during the move from the DSM-IV to the DSM-5 that were made to diagnostic classifications and criteria for depressive disorders.

\section{DICHOTOMIZING MOOD DISORDERS INTO BIPOLAR DISORDERS AND DEPRESSIVE DISORDERS AND REPLACING MIXED EPISODES WITH MIXED FEATURES}

\begin{abstract}
The dichotomization of the chapter, "Mood Disorders", into two chapters called "Bipolar and Related Disorders" and "Depressive Disorders" has been one of the most notable changes to the diagnostic classifications for depressive disorders made between the DSM-IV and the DSM-5. ${ }^{11,12}$ An odd combination of the classical views of Emil Kraepelin and Karl Leonhard (a follower of Carl Wernicke, Kraepelin's opponent) contributed to the definitions underlying the nosology of mood disorders in the DSM-III and DSM-IV. Kraepelin's classical distinction between dementia praecox (chronic psychosis) and manic-depressive insanity (recurrent mood illness with psychosis) was extended to include manic-depressive illness (nonpsychotic mood episodes) by later researchers. Thus, in line with Wernicke's opposition of Kraepelin's manic-depressive illness concept, Leonhard insisted that manic-depressive illness was composed of two distinctive subtypes including unipolar depression and bipolar disorder, based on findings from genetic research. In the DSM-III, the Kraepelinian separation of schizophrenia from mood disorders was, in an odd way, combined with the Leonhardian dichotomization of mood disorders into the two unipolar and bipolar groupings. Moreover, in the DSM-IV, fol-
\end{abstract}

Table 1. Changes to diagnostic classifications and criteria for depressive disorders between the DSM-IV and the DSM-5

\begin{tabular}{|c|c|}
\hline Changes between the DSM-IV and the DSM-5 & Nosological significance \\
\hline $\begin{array}{l}\text { 1. Mood disorders are split into bipolar disorders } \\
\text { and depressive disorders }\end{array}$ & $\begin{array}{l}\text { 1. Depressive disorders are classified and defined in terms of } \\
\text { the deconstruction of the Kraepelinian dualism }\end{array}$ \\
\hline \multicolumn{2}{|l|}{$\begin{array}{l}\text { 2. Mixed episodes are replaced by a new specifier: } \\
\text { "with mixed features" }\end{array}$} \\
\hline $\begin{array}{l}\text { 3. "Hopelessness" is newly added to the subjective descriptors } \\
\text { of depressive mood }\end{array}$ & $\begin{array}{l}\text { 2. The diagnostic threshold for major depressive disorder } \\
\text { is lowered according to a dimensional approach }\end{array}$ \\
\hline \multicolumn{2}{|l|}{$\begin{array}{l}\text { 4. "Bereavement exclusion" is eliminated from the definition } \\
\text { of major depressive disorder }\end{array}$} \\
\hline $\begin{array}{l}\text { 5. The specifier "with psychotic features" can be coded not only } \\
\text { for severe major depressive episodes but also for mild } \\
\text { and moderate major depressive episodes and dysthymia }\end{array}$ & $\begin{array}{l}\text { 3. The "severity-of-psychosis hypothesis," which denotes that } \\
\text { psychotic symptoms are limited to severe depression, is rejected }\end{array}$ \\
\hline $\begin{array}{l}\text { 6. The specifier "with anxious distress" is introduced to describe } \\
\text { the presence of anxious symptoms, graded as mild, moderate, } \\
\text { or severe. }\end{array}$ & $\begin{array}{l}\text { 4. A closer link between generalized anxiety disorder and major } \\
\text { depressive disorder rather than other anxiety disorders } \\
\text { is described by the specifier "with anxious distress" }\end{array}$ \\
\hline
\end{tabular}


lowing a rather pragmatic approach, the unipolar depression concept was expanded to major depressive disorder (MDD), potentially influenced by a preference to prescribe antidepressants rather than lithium and neuroleptics, due to side effects. ${ }^{13-16}$ The finding that bipolar and depressive disorders overlap symptomatically and genetically to a degree that is similar to schizophrenia and depressive disorders led to the dichotomization of mood disorders into bipolar disorders and depressive disorders in the DSM-5. ${ }^{17-19}$ The dichotomization into bipolar disorders and depressive disorders is thus consistent with the deconstruction of the Kraepelinian dualism for psychoses, which denotes the reclassification of schizophrenia and bipolar disorder in terms of a dimensional rather than a categorical approach. ${ }^{13-16}$ From the perspective of a paradigm shift from a categorical to a dimensional approach, the dichotomization of mood disorders carries nosological significance, in that MDD is now considered to be a distinctive disease entity parallel to schizophrenia and bipolar disorder.

However, the dichotomization into bipolar disorders and depressive disorders is partly inconsistent with the fact that the conversion from depressive disorders to bipolar disorders is one of the most significant conversions to occur in psychiatric taxonomy ${ }^{20,21}$ It has been speculated that the completely distinctive definitions of predominantly manic and depressive episodes may have contributed to the removal of the "mixed episode" type in the DSM-5. Moreover, the dichotomization has been theoretically or nosologically supplemented by the replacement of the "mixed episode" with a new coding specifier, "with mixed features," in the DSM-5. ${ }^{11,12}$ The "mixed episode" has been conceptualized in the DSM-IV from the perspective of a categorical approach, whereas the "with mixed features" in the DSM- 5 has been defined from the perspective of a dimensional approach. The specifier "with mixed features" can be coded during all episodes-manic, hypomanic, or depressive. Further, the subthreshold bipolar features during a predominantly depressive episode are coded by the specifier "with mixed features," denoting the presence of at least three of seven hypomanic symptoms including elevated mood, inflated self-esteem, pressure of speech, racing thoughts, goal-directed activity, involvement in risky activities, and decreased need for sleep. However, arguments have been raised that hypomanic expansive symptoms in mixed depression have rarely been reported in previous studies and that mixed depression is a separate condition in the context of mood disorders. ${ }^{22-24}$ Moreover, recent studies have reported that major depressive episode (MDE) mixed features are characterized by a low prevalence, the predominance of anxious distress, the prevalence of cluster B personality disorders, and pharmacological treatment with antipsychotics. ${ }^{25-27}$ Thus, as shown in Figure 1, the specifier "with

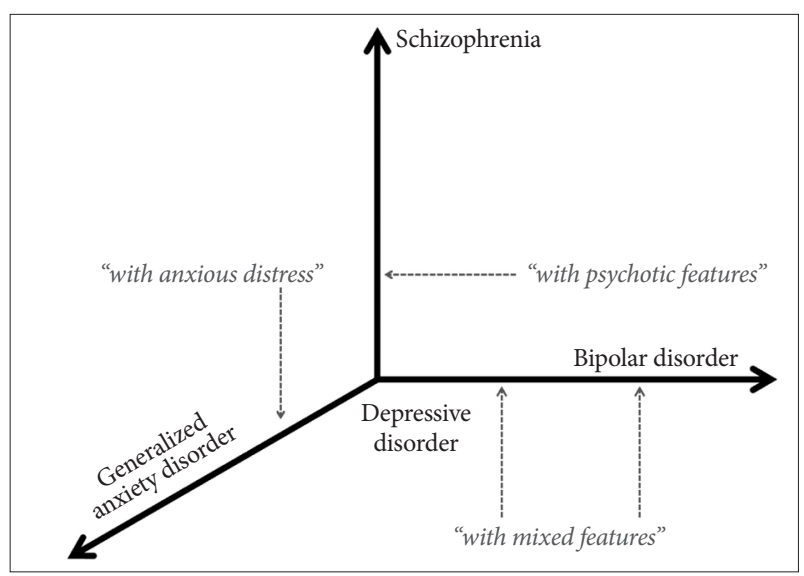

Figure 1. Transdiagnostic specifiers for depressive disorders in the DSM-5.

mixed features" may indicate quantitative but not qualitative overlapping symptoms from one pole to the opposite pole in the dichotomization of mood disorders into bipolar and depressive disorders.

\section{ADDITION OF "HOPELESSNESS" TO THE SUBJECTIVE DESCRIPTORS OF DEPRESSIVE MOOD AND THE ELIMINATION OF "BEREAVEMENT EXCLUSION" FROM THE DEFINITION OF MDD}

The term "hopelessness," which is consistent with the mention of a "black and pessimistic view of the future" contained in the definition of depressive mood in the International Classification of Disease, 10th revision (ICD-10), has newly been added to the subjective descriptors of depressive mood in the DSM-5. ${ }^{11,12}$ Since "hopelessness" is regarded as a cognitive attitude of pessimism rather than a specific emotional state and since it can be present despite the absence of depressive mood, it represents a distinctive feature. In addition, the "bereavement exclusion" has been eliminated from the definition of MDD in the DSM-5, based on the few significant differentiating clinical features between bereavement-related and bereavement-unrelated depressive disorders and the characterization of bereavement-related MDD with past personal histories and family histories of MDEs. ${ }^{28-30}$ The addition of "hopelessness" to the subjective descriptors of depressive mood has therefore broadened the diagnosis of MDD.

Separately, the elimination of the "bereavement exclusion" from the definition of MDD has likely lowered the diagnostic threshold for MDD and contributed to the medicalization of normal grief. As the less severe forms of MDD, such as lowsymptom and non-melancholic MDD, are characterized by lower recurrence rates as compared with other forms of 
$\mathrm{MDD}^{31-33}$ the appropriate threshold for the differentiation of MDD from normal sadness needs to be further explored and precisely defined in the context of either a categorical or a dimensional approach.

\section{WITTGENSTEIN'S “GAMES” ANALOGY AND THE HETEROGENEITY OF MDD}

Although a simplified list of the symptom criteria for MDD, consisting of low mood, loss of interest or pleasure, guilt/worthlessness, impaired concentration/indecision, and suicidal thoughts, has been developed by Zimmerman et al., ${ }^{34}$ the list of nine depressive symptoms as inclusion criteria for MDD has not been changed between the DSM-IV and the DSM-5. The presence of at least five symptoms from a list of nine inclusion criteria, at least one of which should be either low mood or anhedonia, is required to fulfill the DSM-IV/DSM- 5 diagnostic criteria for MDD. A total of 227 different combinations of five or more symptoms can thus fulfill the diagnostic criteria for $\mathrm{MDD} \cdot{ }^{35}$ Considering real clinical situations, 170 and 119 different depressive symptom combinations have been identified in 1,566 patients with MDD diagnosed with the DSM-IV in the Rhode Island Methods to Improve Diagnostic Assessment and Services (MIDAS) project ${ }^{36}$ and in 853 patients with MDD diagnosed with the DSM-IV in the Clinical Research Center for Depression (CRESCEND) study, ${ }^{37}$ respectively. Moreover, either multiple or alternative compounds simultaneously define one inclusion criterion among the six MDD symptom criteria, including psychomotor agitation/retardation, impaired concentration/indecisiveness, worthlessness/guilt, insomnia/hypersomnia, decreased/increased appetite, and death wish/suicidal ideation. Thus, if each component symptom of the six complex criteria is separated, a total of 14,528 different depressive symptom combinations can fulfill the diagnostic criteria for MDD. ${ }^{36}$ Furthermore, the heterogeneity of MDD is inconsistent with the disease essentialism paradigm that the operational criteria for mental disorders enable one to discover the essential neurobiological underpinnings of observable symptoms or signs from the perspective of the categorical approach for classifying mental disorders. ${ }^{11,12}$

Ludwig Wittgenstein (1889-1951), a representative analytical philosopher, had a profound influence on logical positivism and language philosophy. In the context of Wittgenstein's theory, the misconceptions that a psychiatric diagnosis indicates a particular mental process in terms of a categorical approach can be mainly criticized according to the concepts of "family resemblance" and "essence." An analogy involving the concept of "games" has been offered previously by Wittgenstein and is as follows ${ }^{38}$ :
Consider, for example, the proceedings that we call games. I mean board-games, card-games, ball-games, Olympic games, and so on. What is common to them all?-don't say "there must be something common, or they would not be called games"-but look and see whether there is anything common to all. For, if you look at them, you will not see something that is common to all, but similarities, relationships, and a whole series of them at that. To repeat: don't think, but look! ... the concept game is a concept with blurred edges. "But, is a blurred concept a concept at all?" Is an indistinct photograph a picture of a person at all? Is it even always an advantage to replace an indistinct picture [with] a sharp one? Isn't the indistinct one often exactly what we need? ${ }^{39}$

Rosenman and $\mathrm{Nasti}^{38}$ regarded the operational diagnostic criteria of MDD as a corresponding equivalent to Wittgenstein's "games" analogy, based on the fact that cases of depression are related not by an "essence" but instead by extensions of meaning in terms of the heterogeneity of MDD. Namely, a single or "essential" characteristic cannot be identified from cases of MDD that are connected by a set of "family resemblances." In addition, from the perspective of psychiatric taxonomy, the diagnostic boundaries among psychiatric categories are mainly characterized by their boundlessness.

\section{NETWORK ANALYSIS OF MDD SYMPTOMS AND OTHER ELEMENTS}

\footnotetext{
"Symptomics," a new paradigm that describes symptombased rather than diagnosis-based analysis, has been proposed to describe more detailed clinical features (including transdiagnostic symptoms) in the field of mental disorders. Symptomics methods are used to analyze the potential causal interrelations among symptom networks and to understand psychopathology at the level of the individual, not the diagnosis. ${ }^{40,41}$ Based on the symptomics framework, psychiatric diagnoses are considered collections of interrelated symptoms or symptom clusters; network analysis is then used to explore the map of connections and eventual dynamic influences among symptoms and other elements including risk factors, biomarkers, and treatment responses in the field of mental disorders. ${ }^{42-45}$ Network analysis is also used to evaluate the properties of the network as a whole and to determine whether or not these properties contribute to adaptive functioning within the network. ${ }^{46}$ Moreover, network analysis is employed to evaluate the elements that disproportionally contribute to adaptive function within the network. Because "centrality" is defined as the overall connectivity of a symptom in the net-
} 
work structure, central symptoms may have a greater influence on the entire network than peripheral symptoms, and these central symptoms may facilitate interrelations between symptoms within the structure. ${ }^{47,48}$

Network analyses performed to evaluate interactions between depressive symptoms over time have reported weaker associations between depressive symptoms in subjects with depression in remission ${ }^{49}$ and diminished connectivity among symptoms after an intervention. ${ }^{50}$ Network analyses to evaluate interactions between depressive symptoms and other clinical elements have also revealed connections between depressive symptoms and stressful life events ${ }^{51}$ and relationships between stress, biomarkers, and depression. ${ }^{52}$ The most remarkable findings of such network analyses regarding concurrent symptoms in patients with MDD are as follows: first, DSM symptoms were not more central than non-DSM symptoms in a network analysis of 28 depressive symptoms in 3,463 outpatients with depression, as part of the Sequenced Treatment Alternatives to Relieve Depression (STAR*D) study. In fact, the same network analysis identified energy loss (DSM vegetative symptom), sad mood (DSM emotional symptom), and sympathetic arousal (non-DSM symptom) as the most central symptoms of MDD. ${ }^{47}$ These findings are consistent with the observation that the most central symptoms in individuals experiencing chronic pain are difficulty with concentration, loss of interest, depressed mood, and fatigue. ${ }^{53}$ These findings are also in line with the fact that different forms of depression are related not by an essential mental process but instead by a set of "family resemblances," which denotes extensions of meaning in terms of Wittgenstein's "games" analogy. ${ }^{38}$ However, they support neither the operational definition that depressive symptoms are equivalent to indicators of MDD nor the categorical approach assumption that DSM symptoms have greater clinical relevance than non-DSM symptoms in terms of defining MDD. The findings do support the notions that depressive syndrome rather than depressive disease may be the more appropriate therapeutic target, and that symptom-based rather than diagnosis-based antidepressant selection may be a more suitable pharmacological treatment strategy.

\section{ISSUES IN THE CLASSIFICATION OF PSYCHOTIC DEPRESSION}

Psychotic depression is defined as depression accompanied by psychotic symptoms such as delusions and hallucinations. ${ }^{11,12,54}$ Beyond the mere psychotic symptoms, psychotic depression is clinically discriminated from nonpsychotic depression in terms of a greater severity of depressive episodes; greater level of psychomotor disturbance; higher rates of rumination and insomnia; greater deficits in cognitive perfor- mance; longer duration of each subsequent episode; greater vulnerability of conversion to bipolar disorder; greater risk of psychosis in recurrent episodes; and greater rates of mortality, suicide, suicidal attempts, and suicidal ideation. ${ }^{55-61}$ Further, psychotic depression is neurobiologically differentiated from nonpsychotic depression by way of the observation of increased activity of the hypothalamic-pituitary-adrenal axis, a greater rate of cortisol nonsuppression according to the dexamethasone suppression test, smaller volumes of the higher associative regions of the frontal and insular cortices, and a lower activity rate of dopamine- $\beta$-hydoxylase. ${ }^{62-70}$ Therapeutic benefits in patients with psychotic depression have been observed after competitively antagonizing cortisol at the glucocorticoid receptor with mifepristone. ${ }^{71}$ It has thus been suggested that psychotic depression may be a clinically distinctive entity rather than a subtype of MDD. However, psychotic depression is still listed as a subtype of depressive disorders (dysthymia and MDD), using the specifier "with psychotic features," in the DSM-5. ${ }^{11,12,54}$

Because psychotic depression has previously been conceptualized in terms of the "severity-of-psychosis hypothesis" that considers psychotic symptoms to be dependent on the severity of the depressive episode, "with psychotic features" is allowed to be coded only for severe MDEs in the DSM-IV. ${ }^{72-74}$ In terms of deconstructing the Kraepelinian dualism, the white paper for the DSM-5 declares that psychotic symptoms can co-occur regardless of the severity of the depressive episode $^{75}$; as Figure 1 indicates, "with psychotic features" should be more adequately defined, and unipolar and bipolar psychotic depression are clinically related and overlap. Also, the "severity-of-psychosis hypothesis" has been rejected by several studies. The specifier "with psychotic features" can thus be coded for dysthymia and mild and moderate MDEs as well as for severe MDEs in the DSM-5. ${ }^{11,12,54}$

To evaluate the depressive and/or psychotic symptom domains of psychotic depression, 14 non-self-rated and symptom-based scales have been used. The review by Østergaard et al. ${ }^{76}$ classified the 14 symptom-based scales for psychotic depression into four subgroups, including the scales predominantly covering depressive symptoms [i.e., the 17-item Hamilton Depression Rating Scale (HAMD-17), 21-item Hamilton Depression Rating Scale (HAMD-21), 24-item Hamilton Depression Rating Scale (HAMD-24), Modified Hamilton Depression Rating Scale (MHRSD), Montgomery-Asberg Depression Rating Scale (MADRS), Bech-Rafaelsen Melancholia Scale (MES), and Calgary Depression Rating Scale (CDS)]; those predominantly covering psychotic symptoms [i.e., the Brief Psychiatric Rating Scale (BPRS)], Spiker Psychoticism Scale (SPS), and Positive and Negative Symptom Scale (PANSS); those predominantly covering delusions [i.e., the Delusion Se- 
verity Item of the Schedule for Affective Disorders and Schizophrenia (SADS), Dimensions of Delusion Experience Rating Scale (DDRES), and Delusion Assessment Scale (DAS)]; and those covering both depressive and psychotic symptoms [i.e., the Psychotic Depression Assessment Scale (PDAS)].

Among all of these, the PDAS is the only validated scale to evaluate the holistic aspects of psychotic depression. The PDAS consists of 11 items derived from six items of the HAMD-17 (somatic symptoms including general, work and activities, depressed mood, psychic anxiety, guilt feeling, and psychomotor retardation) and five items of the BPRS (emotional withdrawal, suspiciousness, hallucinations, unusual thought content, and blunted affect). The scores on the BPRS items must be converted using the formula (BPRS- 1 ) $\times 2 / 3$ because the scores on the HAMD-17 range from zero to four points and the scores on the BPRS range from one to seven points. Using data from a 12 -week randomized controlled trial of olanzapine+sertraline $(n=129)$ and olanzapine+placebo $(\mathrm{n}=130)$, the relative superiority of the PDAS over both the HAMD-6 and HAMD-17 has been demonstrated in terms of the detection of differences in pharmacological treatment responses to psychotic depression. Moreover, the PDAS has been proposed as a useful tool to differentiate psychotic from nonpsychotic depression. Most of all, in an analysis of the data from the CRESCEND study, the BPRS subscale of the PDAS showed an effective screening ability to discriminate psychotic from nonpsychotic depression, with a cutoff score of one point (sensitivity $=71.2 \%$; specificity $=87.2 \%) .{ }^{76-84}$ The PDAS is thus the only useful validated scale to measure the overall aspects of psychotic depression and discriminate psychotic from nonpsychotic depression, even though it does not cover cognitive symptoms, formal thought disorders, or suicidal risk. Moreover, a more detailed version with an anchoring score from zero to four points for the PDAS has been developed, with the original English-language version now translated into Korean, Danish, Dutch, Japanese, and Turkish (http://psychoticdepressionassessmentscale.com). The PDAS can thus be considered a promising scale, in terms of considering categorical versus dimensional approaches, to supplement the definition of psychotic depression in the DSM-5.

\section{ISSUES IN THE DIAGNOSES OF DEPRESSION AND GENERALIZED ANXIETY DISORDER}

Diagnosing depression and generalized anxiety disorder (GAD) has been considered one of the most important issues regarding categorical versus dimensional approaches ${ }^{11,12,54}$ and one of the most important matters for the DSM-5 task force to handle while refining their research agenda. ${ }^{85} \mathrm{~A}$ closer rela- tionship between GAD with depressive disorders than with other anxiety disorders including panic disorder, agoraphobia, social phobia, and specific phobia has been reported in several studies. Because of a close link between GAD and MDD at the genetic level, it has been proposed that GAD should be classified under the umbrella of depressive disorders, within a continuum from depression to anxiety disorders, rather than on the basis of a dichotomous distinction between depression and anxiety disorders. However, while associated symptom criterion changes for GAD have been proposed, the symptom descriptors for GAD have not changed between the DSM-IV and the DSM-5. ${ }^{86,87}$ Transdiagnostic specifiers and dimensional assessment tools may thus represent alternative methods to overcome the restrictions of the categorical approach in the DSM-5 diagnostic classification for depression anxiety disorders. It has been proposed that the overlaps in familial/genetic factors, childhood environment, personality traits, and demographic characteristics between MDD and GAD have contributed to the introduction of the specifier "with anxious distress." As shown in Figure 1, "with anxious distress" is used to describe the presence of at least two among five anxiety symptoms (i.e., feeling keyed up or tense, feeling unusually restless, difficulty concentrating due to worry, fear that something awful will happen, and fear of losing control of oneself) in an MDD patient. The severity of "with anxious distress" is dimensionally graded as mild, moderate, and severe, comparable with the presence of two, three, and four or more of the five anxiety symptoms, respectively. Individuals with MDD "with anxious distress" have been characterized by poorer clinical outcomes than those without anxious distress in a large cohort study. ${ }^{88}$

Moreover, while mixed anxiety and depressive disorder, which denote the presence of subthreshold anxiety and subthreshold depression in the ICD-10, were intended for inclusion in the DSM-5, they were ultimately not included, leading to claims that the dimensional characteristics of the relationship between anxiety disorder and depression have been insufficiently conceptualized in the DSM-5.

\section{CONCLUSION}

It has been suggested that the changes made in diagnostic classifications and criteria for depressive disorders between the DSM-IV and the DSM-5 can be nosologically conceptualized by a combination of categorical and dimensional approaches. Most of all, the dichotomization of mood disorders into bipolar disorders and depressive disorders and the replacement of "mixed episode" with "mixed features" has mainly been influenced by the deconstruction of the Kraepelinian dualism. Also, the addition of "hopelessness" to the 
subjective descriptors of depressive mood and the removal of "bereavement exclusion" from the diagnosis of MDD in the DSM-5 can contribute to a lowering of the diagnostic threshold for MDD, from the perspective of a dimensional approach. The complexity of the diagnostic criteria for MDD in the DSM5 inevitably results an increase in the heterogeneity of MDD, corresponding to the Wittgensteinian "games" analogy, which suggested that the different forms of MDD are not related by a single essential characteristic but instead by "family resemblance," thereby denoting an extension of meanings. Network analyses of MDD symptoms and other clinical elements are needed to further investigate psychopathologies in the context of computational psychiatry. Network analysis findings so far suggest that depressive symptoms are not equivalent to indicators of MDD and that DSM symptoms do not have a greater level of clinical relevance than non-DSM symptoms for the definition of MDD, respectively. In terms of diagnostic issues in psychotic and anxious depression, the transdiagnostic specifiers "with psychotic features" and "with anxious distress" may be alternative or supplementary dimensional methods for overcoming the "boundlessness" caused by the rough categorical classifications for depressive disorders including MDD. Moreover, transdiagnostic dimensional scales including the PDAS may improve measurements of the holistic features of psychotic depression listed in the current nosological definition of the DSM-5.

\section{Acknowledgments}

This work was supported by the National Research Foundation of Korea (NRF) grant funded by the Korea government (MSIT) (2019R1A2C1090146).

\section{Conflicts of Interest}

The authors have no potential conflicts of interest to disclose.

\section{Author Contributions}

Conceptualization: Yong-Ku Kim. Funding acquisition: Seon-Cheol Park. Investigation: Seon-Cheol Park, Yong-Ku Kim. Projected administration: Yong-Ku Kim. Writing_original draf: Seon-Cheol Park, Yong-Ku Kim. Writing_review \& editing: Seon-Cheol Park, Yong-Ku Kim.

\section{ORCID iDs}

$\begin{array}{ll}\text { Yong-Ku Kim } & \text { https://orcid.org/0000-0001-5694-7840 } \\ \text { Seon-Cheol Park } & \text { https://orcid.org/0000-0003-3691-4624 }\end{array}$

\section{REFERENCES}

1. Adam D. Mental health: on the spectrum. Nature 2013;496:416-428.

2. Shorter E. The History of DSM. In: Paris J, Phillips J, Editors. Making the DSM-5: Concepts and Controversies. New York: Springer Nature, 2013, p.3-20.

3. Sadler JZ. Considering the Economy of DSM Alternatives. In: Paris J, Phillips J, Editors. Making the DSM-5: Concepts and Controversies. New York: Springer Nature, 2013, p.21-38.

4. Insel TR. Next-generation treatments for mental disorders. Sci Transl Med 2012;4:155psc19.

5. Insel TR, Cuthbert BN. Brain disorder? Precisely. Science 2015;348:
499-500.

6. Miller G. Beyond DSM: seeking a brain-based classification of mental illness. Science 2010;327:1437.

7. Whooley O, Horowitz AV. The Paradox of Professional Success: Grand Ambition, Furious Resistances, and the Derailment of the DSM-5 Revision Process. New York: Springer Nature, 2013, p.75-92.

8. Assembly of the American Psychiatric Association. Motion on crosscutting dimensions and severity scales. Passed at the annual meeting of American Psychiatric Association. New York; 2012.

9. Frances A. Diagnosing the DSM. The New York Times. 11 May 2012; 19.

10. Kupfer DJ, Regier DA. Neuroscience, clinical evidence, and the future of psychiatric classification in DSM-5. Am J Psychiatry 2011;168:672-674.

11. Uher R, Perlis RH, Henisberg N, Zobel A, Rietschel M, Mors O, et al. Depression symptom dimensions as predictors of antidepressant treatment outcome: Replicable evidence for interest-activity symptoms. Psychol Med 2012;42:967-980.

12. Park SC, Kim YK. Depression in DSM-5: Changes, Controversies and Future Direction. In: Kim YK, Editor. Understanding Depression: Volume 2. Clinical Manifestations, Diagnosis and Treatment. New York: Springer Nature, 2018, p.3-14.

13. Ghaemi SN. Understanding Mood Disorders: Karl Jaspers' Biological Existentialism. In: Stanghellini G, Fuchs T, Editors. One Century of Karl Jaspers' General Psychopathology. Oxford: Oxford University Press, 2013, p.245-257.

14. Engstrom EJ, Kendler KS. Emil Kraepelin: icon and reality. Am J Psychiatry 2015;172:1190-1196.

15. Kendler KS, Engrom EJ. Criticisms of Kraepelin's psychiatric nosology: 1896-1927. Am J Psychiatry 2018;175:316-326.

16. Park SC. Karl Jaspers' general psychopathology (allgemeine psychopathologie) and its implication for the current psychiatry. Psychiatry Investig 2019;16:99-108.

17. Lichtenstein P, Yip BH, Bjork C, Pawitan Y, Cannon TD, Sullivan PF, et al. Common genetic determinants of schizophrenia and bipolar disorder in Swedish families: a population-based study. Lancet 2009;373: 234-239.

18. Rasic D, Hajek T, Alda M, Uher R. Risk of mental illness in off-spring of parents with schizophrenia, bipolar disorder, and major depressive disorder: a meta-analysis of family high-risk studies. Schizophr Bull 2013;40:28-38.

19. Cross-Disorder Group of the Psychiatric Genomics Consortium, Lee SH, Ripke S, Neale BM, Faraone SV, Purcell SM, et al. Genetic relationship between five psychiatric disorders estimated from genome-wide SNPs. Nat Genet 2013;45:984-994.

20. Berk M, Berk L, Moss K, Dodd S, Malhi GS. Diagnosing bipolar disorder: how can we do it better? Med J Aust 2016;184:459-462.

21. Etain B, Lajnef M, Bellivier F, Mathiey F, Raust A, Cochet B, et al. Clinical expression of bipolar disorder type I as a function of age and polarity at onset: convergent findings in samples from France and the United States. J Clin Psychiatry 2012;73:e561-e566.

22. Moller HJ, Bandelow B, Bauer M, Hampel H, Herpertz SC, Soyka M, et al. DSM-5 reviewed from different angles: goal attainment, rationality, use of evidence, consequence - Part 1: general aspects and paradigmatic discussion of depressive disorders. Eur Arch Psychiatry Clin Neurosci 2015;265:5-18.

23. Zimmerman M, Chelminski I, Young D, Dalrymple J, Matinez JH. A clinically useful self-report measure of the DSM-5 mixed features specifier of major depressive disorder. J Affect Disord 2014;168:357-362.

24. Koulopoulos A, Sani G, Ghaemi SN. Mixed features of depression: why DSM-5 is wrong (and so was DSM-IV). Br J Psychiatry 2013;203:3-5.

25. Park YM. The mixed-features specifier of major depressive disorder in DSM-5: is it practical? Psychiatry Investig 2018;15:1009-1010.

26. Shim IH, Bahk WM, Woo YS, Yoon BH. Pharmacological treatment of major depressive episodes with mixed features: a systematic review. Clin Psychopharmacol Neurosci 2018;16:376-382.

27. Shim IH, Lee J, Kim MD, Jung YE, Min KJ, Kwon YJ, et al. The preva- 
lence and diagnostic classification of mixed features in patients with major depressive episodes: a multicenter study based on the DSM-5. Int J Methods Psychiatr Res 2019: e1773.

28. Greene GM. The relationship between depression and hopelessness: implications for current theories of depression. Br J Psychiatry 1993; 154:650-659.

29. Beck AT, Steer RA, Beck JS, Newman CF. Hopelessness, depression, suicidal ideation, and clinical diagnosis of depression. Suicide Life Threat Behav 1993;23:139-145.

30. Joiner TE Jr, Steer RA, Abramson LY, Alloy LB, Metalsky GI, Schmidt NB. Hopelessness depression as a distinct dimension of depressive symptoms among clinical and non-clinical samples. Behav Res Ther 2001;39:523-536.

31. Zisook S, Corruble E, Duan N, Iglewicz A, Karam EG, Lanouette N, et al. The bereavement exclusion and DSM-5. Depress Anxiety 2012;29: 425-443.

32. Bandini J. The medicalization of bereavement: $(\mathrm{Ab})$ normal grief in the DSM-5. Death Stud 2015;39:347-352.

33. Pies RW. The bereavement exclusion and DSM-5: an update and commentary. Innov Clin Neurosci 2014;11:19-22.

34. Zimmerman M, Galione JN, Chelminski I, McGlinchery JB, Young D, Dalrymple K, et al. A simpler definition of major depressive disorder. Psychol Med 2010;40:451-457.

35. Østergaard SD, Jensen SOW, Bech P. The heterogeneity of the depressive syndrome: when numbers get serious. Acta Psychiatr Scand 2011; 124:495-496.

36. Zimmerman M, Ellison W, Young D, Chelminski I, Dalrymple K. How many different ways do patients meet the diagnostic criteria for major depressive disorder. Compr Psychiatry 2015;56:29-34.

37. Park SC, Kim JM, Jun TY, Lee MS, Kim JB, Yim HW, et al. How many different symptom combinations fulfill the diagnostic criteria for major depressive disorder?: results from the CRESCEND study. Nord J Psychiatry 2017;71:217-222.

38. Rosenman S, Nasti J. Psychiatric diagnoses are not mental processes: Wittgenstein on conceptual confusion. Aust N Z J Psychiatry 2012;46: 1046-1052.

39. Wittgenstein L. Philosophical Investigations. (German Text, with a Revised English Translation, Trans GEM Anscombe), 3rd Edition. Oxford: Blackwell; 2001.

40. Armour C, Fried EI, Olff M. PTSD symptomics: network analyses in the field of psychotraumatology. Eur J Psychotraumatol 2017;8(sup3): 1398003.

41. Fried EI. Moving forward: how depression heterogeneity hinders progress in treatment and research. Expert Rev Neurother 2017;17: 423-425.

42. Bentall RP, Wickham S, Shevlin M, Varese F. Do specific early-life adversities lead to specific symptoms of psychosis? A study from the 2007 the adult psychiatric morbidity survey. Schizophr Bull 2012;38: 734-740.

43. Fried EI, Nesse RM. Depression is not a consistent syndrome: an investigation of unique symptom patterns in the STAR ${ }^{\star} \mathrm{D}$ study. J Affect Disord 2015;172:96-102.

44. Hieronymus F, Emilsson JF, Nilsson S, Eriksson E. Consistent superiority of selective serotonin reuptake inhibitors over placebo in reducing depressed mood in patients with major depression. Mol Psychiatry 2016;21:523-530.

45. Persons JB. The advantages of studying psychological phenomena rather than psychiatric diagnoses. Am Psychol 1986;41:1252-1260.

46. Contreas A, Nieto I, Valiente C, Espinosa R, Vazquez. The study of psychopathology from the network analysis perspective: a systematic review. Psychother Psychosom 2019;88:71-83.

47. Fried EI, Epskamp S, Nesse RM, Tuerlinckx F, Borsboom D. What are 'good' depressive symptoms? Comparing the centrality of DSM and non-DSM symptoms of depression in a network analysis. J Affect Disord 2016;189:314-320.

48. Opsahl T, Agneessens F, Skvoretz J. Node centrality in weighted net- works: generalizing degrees and shortest paths. Soc Netw 2010;32: 245-251.

49. van Borkulo C, Boschloo L, Borsboom D, Pennix BW, Waldorp LJ, Schoevers RA. Association of symptom network structure with the course of longitudinal depression. JAMA Psychiatry 2015;72:1219-1226.

50. Madhoo M, Levine SZ. Network analysis of the Quick Inventory of Depressive Symptomatology: Reanalysis of the STAR ${ }^{\star} \mathrm{D}$ clinical trial. Eur Neuropsychopharmacol 2016;26:1768-1774.

51. Cramer AO, Borsboom D, Aggen SH, Kendler KS. The psychopathology of dysphoric episodes: differential impact of stressful life events on the pattern of depressive symptom inter-correlations. Psychol Med 2012;42:957-965.

52. Santos H Jr, Fried EI, Asafu-Adjei J, Ruiz RJ. Network structure of perinatal depressive symptoms in Latinas: relationship to stress and reproductive biomarkers. Res Nurs Health 2017;40:218-228.

53. McWilliams LA, Sarty G, Kowal J, Wilson KG. A network analysis of depressive symptoms individuals seeking treatment for chronic pain. Clin J Pain 2017;33:899-904.

54. Park SC, Choi J. Issues in the Classification of Psychotic Depression. In: Kim YK, Editor. Major Depressive Disorder: Risk Factors, Characteristics and Treatment Options. New York: NOVA Science Publishers Inc., 2017, p.49-67.

55. Østergaard SD, Rothschild AJ, Uggerby P, Munk-Jørgensen P, Bech P, Mors O. Considerations on the ICD-11 classification of psychotic depression. Psychother Psychosom 2012;81:135-144.

56. Keller J, Schatzberg AF, Maj M. Current issues in the classification of psychotic major depression. Schizophr Bull 2007;33:877-885.

57. Glassman AH, Roose SP. Delusional depression: a distinct clinical entity? Arch Gen Psychiatry 1981;138:831-833.

58. Lykouras E, Malliara D, Christoodoulou GN, Papakostas Y, Voulgari A, Tzonou A, et al. Delusional depression: phenomenology and response to treatment. A prospective study. Acta Psychiatr Scand 1986; 73:324-329.

59. Frances A, Brown RP, Kocsis JH, Mann JJ. Psychotic depression: a separate entity? Am J Psychiatry 1981;138:831-833.

60. Zaninotto L, Gulielmo R, Calati R, Ioime L, Camardes G, Janiri L, et al. Cognitive markers of psychotic unipolar depression: a meta-analytic study. J Affect Disord 2015;174:580-588.

61. Hill SK, Keshavan MS, Thase ME, Sweeney JA. Neuropsychological dysfunction in antipsychotic-naïve first-episode unipolar psychotic depression. Am J Psychiatry 2014;161:996-1003.

62. Anton RF. Urinary free cortisol in psychotic depression. Biol Psychiatry 1987;22:24-34.

63. Nelson JC, Davis JM. DST studies in psychotic depression: a metaanalysis. Am J Psychiatry 1997;154:1497-1503.

64. Rosthschild AJ, Schatzberg AF, Rosenbaum AH, Stahl JB, Cole JO. The dexamethasone suppression test as a discriminator among subtypes of psychotic patients. Br J Psychiatry 1982;141:471-474.

65. Schatzberg AF, Rothschild AJ, Stahl JB, Bond TC, Rosenbaum AH, Lofgren SB, et al. The dexamethasone suppression test: Identification of subtypes of depression. Am J Psychiatry 1983;140:88-91.

66. Kim DK, Kim BL, Sohn SE, Lim SW, Na DG, Paik CH, et al. Candidate neuroanatomic substrates of psychosis in old-aged depression. Prog Neuropsychopharmacol Biol Psychiatry 1999;23:793-807.

67. Salokangas RK, Cannon T, van Erp T, Ilonen T, Taiminen T, Karlsson $\mathrm{H}$, et al. Structural magnetic resonance imaging in patients with firstepisode schizophrenia, psychotic and severe non-psychotic depression and healthy controls: results of the schizophrenia and affective psychoses (SAP) project. Br J Psychiatry Suppl 2012;43:S58-S65.

68. Simpson S, Baldwin RC, Jackson A, Burns A. The differentiation of DSM-III-R psychotic depression in later life from nonpsychotic depression: comparisons of brain changes measured by multispectral analysis of magnetic resonance brain images, neuropsychological findings, and clinical features. Biol Psychiatry 1999;45:193-204.

69. Cubells JF, Price LH, Meyers BA, Anderson GM, Zabetian CP, Alexo- 
poulos GS, et al. Genotype-controlled analysis of plasma dopamine beta-hydroxylase activity in psychotic unipolar major depression. Biol Psychiatry 2002;51:358-364.

70. Meyers BS, Alexopoulos GS, Kakuma T, Tirumalasetti F, Gabriele M, Alpert S, et al. Decreased dopamine beta-hyrodoxylase activity in unipolar geriatirc delusional depression. Biol Psychiatry 1999;45:448-452.

71. Block TS, Kushner H, Kalin N, Nelson C, Belanoff J, Schatzberg A. Combined analysis of mifepristone for psychotic depression: plasma levels associated with clinical response. Biol Psychiatry 2018;84:46-54.

72. Østergaard SD, Bille J, Søltoft-Jensen H, Lauge N, Bech P. The validity of severity-psychosis hypothesis in depression. J Affect Disord 2012; 140:48-56.

73. Maj M, Pirozzi R, Magliano L, Fiorillo A, Bartoli L. Phenomenology and prognostic significance of delusions in major depressive disorder: a 10year prospective follow-up study. J Clin Psychiatry 2007;68:1411-1417.

74. Ohayon MM, Schatzberg AF. Prevalence of depressive episodes with psychotic features in general population. Am J Psychiatry 2002;159: 1855-1861.

75. Tamminga CA, Sirovatka PJ, Regier DA, van Os J. Deconstructing Psychosis: Refining the Research Agenda for DSM-V. Washington, D.C.: American Psychiatric Association; 2010.

76. Østergaard SD, Rothschild AJ, Flint AJ, Mulsant BH, Whyte EM, Leadholm AK, et al. Rating scale measuring the severity of psychotic depression. Acta Psychiatr Scand 2015;132:335-344.

77. Østergaard SD, Meyers BS, Flint AJ, Mulsant BH, Whyte EM, Ulbricht CM, et al. Measuring psychotic depression. Acta Psychiatr Scand 2014; 129:211-220.

78. Østergaard SD, Meyers BS, Flint AJ, Mulsant BH, Whyte EM, Ulbricht $\mathrm{CM}$, et al. Measuring treatment response in psychotic depression: he psychotic depression assessment scale (PDAS) takes both depressive and psychotic symptoms into account. J Affect Disord 2014;160:68-73.

79. Østergaard SD, Pedersen C, Uggerby P, Munk-Jørgensen P, Rothschild AJ, Larsen JI, et al. Clinical and psychometric validation of the psychotic depression assessment scale. J Affect Disord 2015;173:261-268.

80. Østergaard SD, Rothschild AJ, Flint AJ, Mulsant BH, Whyte EM, Ver- meulen T, et al. Establishing the cut-off score for remission and severity-ranges on the psychotic depression assessment scale (PDAS). J Affect Disord 2016;190:111-114.

81. Leadholm AK, Rothschild AJ, Nolen WA, Bech P, Munk-Jørgensen P, Østergaard SD. The treatment of psychotic depression: is there consensus among guidelines and psychiatrists? J Affect Disord 2013;145: 214-220.

82. Park SC, Choi J, Kim JM, Jun TY, Kim JB, Yim HW, et al. Is the psychotic depression assessment scale a useful diagnostic tool?: the CRESCEND Study. J Affect Disord 2014;166:79-85.

83. Park SC, Østergaard SD, Choi J, Kim JM, Jun TY, Lee MS, et al. Is the BPRS-5 subscale of the psychotic depression assessment scale a reliable screening tool for psychotic depression?: results from the CRESCEND Study. J Affect Disord 2015;174:188-191.

84. Park SC, Jang EY, Kim JM, Jun TY, Lee MS, Kim JB, et al. Clinical validation of the Psychotic Depression Assessment Scale, Hamilton Depression Rating Scale-6, and Brief Psychiatric Rating Scale-5: results from the clinical research center for depression study. Psychiatry Investig 2017;14:568-576.

85. Goldberg D, Kendler KS, Sirovata PJ, Regier DA. Diagnostic Issues in Depression and Generalized Anxiety Disorder: Refining the Research Agenda for DSM-V. Washington, D.C.: American Psychiatric Association; 2010.

86. Starcevic V, Portman ME. The status quo as a good outcome: how the DSM-5 diagnostic criteria for generalized anxiety disorder remained unchanged from the DSM-IV criteria. Aust N Z J Psychiatry 2013;47: 995-997.

87. Karlsson B, Sistrom R, Ostling S, Waern M, Borjesson-Hanson A, Skoog I. DSM-IV and DSM-5 prevalence of social anxiety disorder in a population sample of older people. Am J Geriatr Psychiatry 2016;24: 1237-1245.

88. Gaspesz R, Lamers F, Kent JM, Beekman AT, Smit JH, van Hemert $\mathrm{AM}$, et al. Longitudinal predictive validity of the DSM-5 anxious distress specifier for clinical outcomes in a large cohort of patients with major depressive disorder. J Clin Psychiatry 2017;78:207-213. 